\title{
Alternative Fuel Use in Iraq: A way to Reduce Air Pollution
}

\author{
Jafaar A. Kadhem, Khalid S. Reza, Wahab K Ahmed
}

\begin{abstract}
The Iraq air is polluted highly by pollutants emitted from automobiles and trucks as well as power stations. This pollution resource is well known it is the burning of oil and natural gas. Iraq has been subjected to a series of wars and economic blockade for more than 40 continuing years. The war and blockade conditions have affected all the country's infrastructure causing huge deterioration in the services provided to Iraqi citizens. The Iraqi refineries as well have been subjected to major destruction and reconstruction several times. Unfortunately, the reconstruction in Iraq conditions was not in appropriate level, and for that reason we find the Iraqi gasoline and diesel are one of the worst fuels in the world. All reports demonstrated that the Iraqi gasoline contains high levels of sulfur $(500 \mathrm{ppm})$, as well as high levels of lead compounds to increase octane. The Iraqi diesel contains sulfur up to 1 to $2.5 \%$ of its weight which makes it the worst globally. In Iraq there are many alternative fuels that generate better engine performance and emit lower exhaust pollutants while improving fuel consumption. This paper reviews some of the Iraqi experimental work during the past ten years and the available results about using gaseous fuels such as natural gas, liquefied petroleum gas and hydrogen. In addition, the study focus on the use of some additives to gasoline and diesel, such as alcohols and biofuels to reduce the effects of sulfur associated with these types of fuel. The Iraqi research works have found many solutions and alternative methods of operation to eliminate the various engines emitted pollutants. The role has now come to the decision makers to legislate the laws and decisions necessary to switch to new types of alternative fuels.
\end{abstract}

Index Terms-Iraq; Alternative fuels; Diesel; Gasoline.

\section{INTRODUCTION}

The amount of fuel spent on the operation of cars, equipment and services reaches $40 \%$ of the amount of oil produced and consumed globally. The burning of these quantities of fuel in the engines of internal combustion produces dangerous pollutants harmful to the environment. Relevant studies have shown that the emissions produced by burning fossil fuels causes severe environmental pollution, acid rain, climate change, and global warming [1]. The whole world is undergoing a major change in climate, including the Middle East region in which Iraq is located [2]. Rising temperatures, low rainfall and severe drought for many years are all manifestations of climate change in the

Published on May 8, 2017.

J. A. Kadhem is with the Energy and Renewable Energies Technology Centre, University of Technology, Iraq, (e-mail: 11023@uotechnology.edu.iq).

K. S. Reza is an assistant lecturer in the Energy and Renewable Energies Technology Centre, University of Technology, Iraq. (e-mail: 140010@ uotechnology.edu.iq)

W. K. Ahmed is an assistant lecturer in the Energy and Renewable Energies Technology Centre, University of Technology, Iraq. (e-mail: 11031@ uotechnology.edu.iq) region [3]-[4]. Since the oil crisis in the 1970s and researchers are studying the possibility of finding different types of alternative fuel for fossil fuels. The results of their studies have also led to major developments in the development of alternative renewable energies for fossil fuels to produce electricity [5]-[22].

Iraq is characterized by being an oil country containing huge reserves of oil and natural gas. This country has suffered numerous wars and economic blockade over the last 40 years. These conditions caused the destruction of the country and the loss of wealth in addition to the deterioration of services and the spread of diseases also caused a high rate of air pollution dramatically. Iraq is suffering today from the decline of water in the Tigris and Euphrates rivers and the increase of their water salinity and suffers also from almost daily dust storms [23],[24]. Electricity is a real dilemma in this oil rich country, as the state has not been able to today to achieve the citizen's electricity and there are interruptions daily arrive during the summer, especially to 16 hours a day. This suffering has driven citizens to use millions of small, medium and large generators that have been imported without control and are dumping millions of tons of pollutants into the atmosphere [25],[26]. Several studies have shown that the main reason for the high concentration of pollutants is the poor quality of Iraqi fuel. This fact can be shown in numbers: Iraqi produced diesel fuel contains from 1 up to $2.5 \%$ sulfur while the gasoline contains $0.5 \%$ of it accompanied with high proportion of toxic lead compounds [27],[28].

In this study we will try to describe and explain the most important Iraqi research in the field of preparing and testing alternative fuels and alternative engines to reduce air pollution resulting from pollutants emitted from them. This review is part of an ongoing effort by the Energy and Renewable Energy Research Center in the University of Technology, Baghdad-IRAQ to improve the environment and reduce air pollution in Iraq. The study focuses on research on the two main fuels in Iraq: gasoline and diesel fuel.

\section{IRAQI DIESEL FUEL}

Iraqi diesel fuel has high sulfur content from $1 \%$ up to $2.5 \%$, and a relatively low cetane number from 42 to 49 , making it one of the worst fuels in the world. The reason refers to the failure of oil refineries in this country because of the economic blockade of more than 14 years and successive wars. Therefore, the Iraqi researcher relied on what is available in the Iraqi environment to improve the properties of diesel combustion and reduce the resulting pollutants. 


\section{A. Add oxygenated alcohols to Iraqi diesel}

The addition of substances that have oxygen in its internal structure (oxygenates), where the most important of it are alcohols, which are available in Iraq, including several types of ethanol and methanol and produced from fossil oil sources or from bio sources.

Reference [29] investigated the performance of a singlecylinder compression ignition engine fueled by added ethanol to diesel fuel at different volume rates. The study has compared the outcomes of this ethanol-diesel engine with the conventional diesel engine for multiple operational conditions such as change in the equivalent ratio, speed, injection timing and load. The addition of ethanol increases the specific fuel consumption at medium and low loads while the fuel consumption is lower than diesel at high loads. There is an improvement in fuel consumption when the load is fixed for ethanol-diesel mixture. The thermal efficiency of the diesel engine is better than that of dieselethanol at medium and light loads. When working at high loads, the diesel-ethanol engine outperforms the diesel engine and improves its efficiency significantly. The researchers found that increasing the proportion of ethanol in the mixture improves the efficiency of the engine in general. Retarding injecting time from the optimum injection timing caused an increase in specific fuel consumption up to $40 \%$ higher than the consumption state at the optimum time, and the thermal efficiency of the dieselethanol engine is generally less than the diesel engine when the injection timing is delayed [30].

Reference [31] compared diesel fuel performance and contaminants when used in a direct injection four-cylinder engine fueled with diesel-ethanol mixtures. The operating conditions were total load and speed of $1500 \mathrm{rpm}$. Ethanoldiesel mixtures emitted low CO contaminants, unburnt hydrocarbons, and NOx. The diesel-ethanol mixture causes an increase in the specific fuel consumption up to $13.8 \%$ due to the low thermal value of ethanol. The results of the study showed the possibility of adding ethanol to diesel fuel without any modifications in the engine.

In [32], the specifications of diesel fuel and mixtures of diesel-methanol were compared using a four-cylinder directinjection engine and a total load of $1500 \mathrm{rpm}$. The results of the study showed that the diesel-methanol mixtures clearly reduce the $\mathrm{CO}$ pollutants, the unburnt $\mathrm{HC}$ hydrocarbons, but cause a limited increase in NOx. The results showed a clear decrease in noise with an increase in the methanol ratio in the burning mixture.

The Iraqi diesel is characterized by its low cetane number, which negatively affects the engine's resulting power. Therefore, [33] used some type of cetane number optimizer with Iraqi diesel fuel and studied the effect of the improvement of the cetane number on the exhaust pollutants. Ethylene-hexyl nitride was added as a cetane improver and it enhanced the diesel fuel cetane number where three numbers of 50, 52 and 55 were used and compared to conventional diesel fuel that has a cetane number of 48.5. The addition of the cetane number improver reduced the specific fuel consumption by $12.5 \%$ and increases the thermal efficiency by $9 \%$. The study found that $\mathrm{CO}$ and UBHC concentrations increased at higher loads compared to primary diesel, and NOx concentrations were slightly higher $(6 \%)$. CO concentrations have been reduced up to $30.7 \%$ for this group. Engine noise was decreased by $10.95 \%$ with the increase in the cetane number of fuel. The results of the study showed the need to improve the quality of diesel fuel produced to achieve clean combustion in the diesel engines.

Reference [34] investigated a three-dimensional study to simulate the dynamics of Iraqi diesel fuel and its combustion. Solid works and ANSYS Design Modeler were used for mechanical drawing and design for all parts of the boiler. A model network using ANSYS Meshing was used and exported to ANSYS FLUENT to illustrate the combustion of Iraqi diesel fuel in theory. The theoretical results coincided with the practical results of the burning of diesel, which proved the success of the simulation process and make all calculated results theoretically were acceptable. This study showed that the use of ANSYS FLUENT is an acceptable engineering tool to predict the flow of fuel, mixing, combustion, particle transport, and the components of exhaust gases $\left(\mathrm{CO}, \mathrm{CO}_{2}\right.$, etc.). It also gives the flow of gases and the irregular distribution of temperature inside the boiler. The use of this model enables the disposal of economically costly and pre-built processes on trial and error and modification of devices to study combustion.

\section{B. Duel fuel}

Iraqi researchers studied the possibility of operating a diesel engine with dual fuel that was second fuel wither liquid or gas to improve the specifications of Iraqi diesel and reduce the sulfur accompanying it and improve its cetane number. The interest of researchers is focused on the effective use of existing energy sources or the development of new sources of fuel that are environmentally friendly. Alternative gas fuels represent several types of fuel that are gaseous in normal weather conditions, and can be used alone or mixed with other fuels. Reference [35] investigated the use of duel fuel in a single-cylinder diesel engine adding liquefied petroleum gas (LPG) to diesel. The study aimed to determine the performance and the pollutants of the engine. Liquefied petroleum gas (primary fuel) is mixed with air in the intake manifold and then compressed and ignited with a small amount of diesel fuel injected. The dual-fuel engine used resulted in a reduction in nitrogen oxides (NOx) emissions for all load loads. The thermal engine efficiency improved by $3 \%$ in this case, and the non-burnt hydrocarbons, carbon monoxide and carbon dioxide emitted from the engine [36].

Reference [37] studied practically the possibility of improving the performance of a compression ignition engine by adding gaseous hydrogen with the air inside the engine. For this purpose, a four-stroke single-cylinder engine with variable compression ratio, injection timing, and equivalent ratio was used when adding hydrogen at different volume rates for diesel fuel. The speed of $1500 \mathrm{rpm}$ and the highest useful compression ratio were selected to study the effect of a wide range of equivalent ratios and injection timing. The results showed that the higher useful compression ratio for diesel fuel used in this study is (17.7: 1), and increases when the mixture of fuels was used. The results of the study showed that the engine can operate at very lean equivalence 
ratio when hydrogen is added. The thermal efficiency is also increased and the fuel consumption of decreased by increasing the hydrogen volume fraction in the mixture to a certain extent.

Reference [38] also examined the performance characteristics and contaminants of the single-cylinder Ricardo engine when it was powered by a dual fuel consisting of natural gas added to Iraqi diesel. The researcher suggested that the largest part of the liberated energy in the combustion chamber is caused by the gas fuel while diesel fuel was fueled as a source of ignition. The study examined the effect of the equivalent ratio, velocity, and injection timing on the specific fuel consumption and the exhaust emissions emitted compared to Iraqi diesel fuel alone. The results of the study showed that working with dual fuel significantly reduced NOx levels in all tested operational conditions. Levels of $\mathrm{CO}, \mathrm{CO}_{2}$, and $\mathrm{HC}$ were somewhat high at lean equivalence ratios and low loads. In addition, the qualitative start-up of fuel was higher in this case compared to diesel fuel.

The combustion noise can be considered to be contaminated with a direct impact on the surrounding environment. Therefore, [39] measured the noise resulting from the use of the multi-cylinder engine, four-stroke after slight modifications to operate with dual fuel diesel and liquefied petroleum gas. He studied the effect of operational variables such as engine load, fuel injection timing, and engine speed. The results of the study showed that the use of liquefied petroleum gas (LPG) as a primary fuel in the dual fuel mixture gives engine noise higher than the use of natural gas $(\mathrm{NG})$ or diesel fuel alone. The results showed that advancing the injection timing away from optimum timing increases the levels of sound pressure.

The burning of diesel fuel produces high levels of PM pollutants, which is one of the most hazardous pollutants on public health, especially the respiratory system, so these pollutants are considered the most dangerous air pollutants. Diesel fuel is characterized by emitting large quantities of this pollutant into the air. Efforts are being made to reduce the emission of this pollutant, including the use of alternative fuels suitable for work in diesel engines. Reference [40] studied the effect of load, velocity, equivalent ratio, injection timing and hydrogen addition rate on the amount of PM emitted from the engine. The study was done using a direct injection multi-cylinder engine. Hydrogen was added with three volume fractions of 30,50 and $70 \%$ in the intake manifold. The study results showed that the addition of hydrogen significantly reduced the emitted PM pollutants. The studied variables also have an impact on the amount of PM produced.

Reference [41] in his practical study has focused on the exhaust pollutants emitted from a direct-injection multicylinder diesel engine during cold operation. Exhaust air pollutants were measured and analyzed in the winter conditions of Baghdad, Iraq, where temperatures are low. The effect of the start-up speed on the emitted exhaust pollutants was studied and the results showed higher levels of $\mathrm{CO}$ and $\mathrm{HC}$ emitted and less $\mathrm{CO}_{2}$. Although operating in cold conditions, concentrations of nitrogen oxides in the exhaust gases appeared. At an engine speed of $800 \mathrm{rpm}$, the smoke went up and engine noise increased as compared to the remaining speeds.

The cold operation of a diesel engine is considered one of the most important stages of combustion that need more research, as large amounts of pollutants are emitted during this period. Part of these pollutants is the result of the failure of instantaneous ignition and incomplete combustion because of the low temperature of the combustion chamber. There are many variables that overlap in this process, most importantly the properties of fuel and the lubrication oil, in addition to the operating conditions. Reference [42] examined the use of a direct-injection multi-cylinder engine to study the effect of injection timing, which is a key role in engine start-up power. Four injection timings $(12,15,20$ \& $\left.23^{\circ} \mathrm{BTDC}\right)$ were selected to operate the engine. The emissions from the engine were compared with standard operation at $17^{\circ} \mathrm{BTDC}$ (factory specification). Four cooling water temperatures were selected for the injection experiments $\left(-10,0,25 \& 50^{\circ} \mathrm{C}\right)$. The results of the study showed that the warming of the cooling water of the engine reduces the period of cold operation clearly. The start-up instability of the engine was apparent during the use of cooling water at temperatures of $\left(0\right.$ and $\left.-10{ }^{\circ} \mathrm{C}\right)$. Very high levels of $\mathrm{CO}, \mathrm{HC}$, and high smoke opacity were present in the exhaust gases during this period. Engine noise also increased due to lower cooling temperatures and delayed injection timing.

\section{Diesel fuel alternatives}

Iraqi researchers studied the addition of many substances other than alcohols to diesel fuel in order to increase the cetane number and reduce the sulfur content. One of these experiments was done by [43] who added water to diesel and forming an emulsion from them. The researcher claimed that the use of water-diesel emulsion would reduce NOx and PM concentrations together. Nitrogen oxides will be reduced due to lower gas temperatures and increased concentrations of $\mathrm{OH}$ reactors. PM concentrations decreased due to the phenomenon of micro-explosion of water. The results of the study showed that the specific consumption of the fuel is slightly improved when adding water at $10 \%$ and $20 \%$ volume. Fuel consumption increased when the volume fraction of used water was $30 \%$. Concentrations $\left(\mathrm{CO}, \mathrm{CO}_{2}\right.$, $\mathrm{UBHC}$ ) were reduced when water was added at $10 \%$ and $20 \%$, as well as NOx and PM levels. At these two addition levels, the engine noise was reduced at all studied engine loads. The author explained that the diesel-water emulsion can be used without any modifications to the fuel system or engine, making it a good fuel and ready to use.

Iraqi researchers have also thought of using biofuels or biodiesel as a non-toxic renewable fuel that can be used in engines without improvements or possibly minor modifications. Biodiesel is currently produced at a high price compared to diesel oil, but with the rapid development of the industry it will, one day, reach competitive prices with the traditional diesel. It can also be produced from lowcost oils (such as restaurant waste, frying oils and animal fat), making it less expensive. Biodiesel production is a major challenge because its raw materials contain high levels of free fatty acids. 
Reference [44] investigated the effect of biodiesel produced from residues and wastes of restaurants on the performance and emission. The researchers have prepared two mixtures of yellow oil consisting of several types of residual edible oil after use in restaurants. Both fuels were studied in their pure state and with a mixture of $20 \%$ biodiesel with stable operating conditions for the fourcylinder engine. Although both biodiesel fuel pumps gave a clear decrease in concentrations of carbon monoxide, nonburnt hydrocarbons and fouling molecules compared to conventional diesel. Nitrogen oxides were increased about 7 to $11 \%$ when using yellow grease B20 and B100, respectively.

Reference [45] used Iraqi sunflower oil as crude oil to produce bio-diesel. The produced fuel conducted by using a chemical transformer with pre-oxidation, wash the product with water to improve fuel specifications more, sedimentation and removal of non-reactant methanol residues and other impurities. Experiments were performed using a direct-injection four-cylinder diesel engine to test engine performance and pollution characteristics when operated with bio-diesel fuel and biodiesel-diesel mixtures and compared with conventional diesel fuel. The results of the study showed that $\mathrm{CO}, \mathrm{CO}_{2}$ and $\mathrm{HC}$ concentrations and noise from fuel uses $100 \%$ bio-diesel were less than 50.03, $11.05,44.48$ and 13\%, respectively. Exhaust gas temperatures are reduced by $25.57 \%$, and the specific fuel consumption of biofuels is increased by $35.7 \%$ and the NOx concentrations were increased by $21.32 \%$.

Bio-diesel was used as a green and clean substitute for fossil fuels by [46]. The researcher produced bio-diesel fuel from Iraqi sunflowers oil using transesterification reaction and tested the bio-diesel produced in several mixing ratios with diesel $(0,20,50,100 \%)$. The results of the study showed that the specific fuels consumption was increased by the use of added bio-diesel to diesel at the speed of the engine at rates of 23, 27 and $37.5 \%$ for biodiesel B20, B50 and B100 respectively compared to diesel separately. In the other hand, the engine's volumetric efficiency improved with the increase of the added bio-diesel. The brake thermal efficiency of biodiesel mixtures was low; the maximum reduction rate reached $3.45 \%$ when $\mathrm{B} 100$ was used. NOx concentrations increased with biodiesel mixtures and with engine speed and load increase due to the availability of oxygen in the biodiesel structure, as well as the necessary heat for the reaction available. $\mathrm{CO}$ and $\mathrm{HC}$ concentrations were high with biodiesel up to $50 \%$.

Reference [47] used corn oil to produce biodiesel and test it in a multi-cylinder engine to evaluate and study the PM emitted from the diesel engine when it fed diesel with a mix of biodiesel and diesel. Since conventional Iraqi diesel has high sulfur content that releases high rates of PM, it is considered the basis of comparison in the tests. The results of the study showed a significant reduction in PM emitted when using biodiesel. The highest decrease in PM concentrations was up to $34.96 \%$ when B100 was used compared with diesel when the engine load was full and the speed was constant (1500 rpm). The researcher also noticed an increase in PM concentration when the injection timing was delayed away from the optimum injection timing. One of the main findings of the study is that biodiesel has a significant effect on smoke in idle mode with a decrease of $8.6,18,39.75 \%$ for $\mathrm{B} 20, \mathrm{~B} 50$ and $\mathrm{B} 100$ respectively compared to diesel. The study concluded that BM concentrations could be further reduced if sulfur content in Iraqi diesel fuel was significantly reduced.

\section{EGR employment to minimize the diesel engine contaminants}

Many Iraqi researchers have studied the most appropriate techniques to reduce pollutants emitted from a diesel engine. Because NOx is the most dangerous contaminant, the exhaust gas recirculation in diesel engines is a technique used to reduce the concentration of this pollutant. Reference [48] used EGR with a four-stroke multi-cylinder direct injection diesel engine. The exhaust gas recycling system was tested in several volumetric fraction ratios of $(0,5,10$, 20 and $30 \%$ ) and studied the effect of EGR rates on CO, $\mathrm{HC}$, NOx and noise. The results showed a significant decrease in $\mathrm{NOx}, \mathrm{CO}_{2}$ and noise concentrations, while $\mathrm{CO}$ and $\mathrm{HC}$ concentrations increased.

Reference [49] carried out his experiments using a direct injection diesel engine by adding EGR with volumetric fraction rates from $0 \%$ till reaching the misfire of the ignition. Also, he used advanced injection timing at $21^{\circ}$ BTDC (before the upper dead center), and retarded inject timing at $12^{\circ} \mathrm{BTDC}$. The results showed that the retarding the injection caused a significant increase in the specific fuel consumption of up to $17 \%$, reduced the thermal efficiency by $20.88 \%$, while the reverse when the injection timing was advanced and the EGR rate was 50\%. The HC, NOx and PM levels and engine noise are significantly lower than that of the engine with pure diesel and without exhaust gas circulation.

Due to the importance of using alternatives to diesel fuel that ethanol is one of the best. Ethanol has disadvantages when it is added to diesel where NOx concentrations increase. Reference [50] tested the effect of the use of a biodiesel ethanol mixed with the EGR on the performance and contaminants of a compression ignition engine. The study focused on the effect of some of the operational variables of the engine such as load, engine speed and injection timing on engine performance and pollutants. To determine the number of experiments, the ratio of ethanol to diesel was fixed at $(10 \%$ ethanol $+90 \%$ diesel $)$, and three ratios of EGR (10, 20 and 30\%) were used. Ethanol mixture has a low evaporation temperature, and the cetane number is low, these disadvantages have been overcome by the addition of a cetane number improver and a solvent that prevents the separation of the two fuels in the tank. The results of the study showed that engine operation with a bio-ethanol-diesel mixture with EGR significantly reduced NOx concentrations as well as engine noise. This engine increased the unburnt hydrocarbons and carbon monoxide. The presence of ethanol with oxygen in its internal structure has contributed to the negative EGR effects that increased concentrations of $\mathrm{HC}$ and $\mathrm{CO}$.

Idle period consumes large quantities of fuel, especially in diesel trucks for heavy service, which reduces the quality of the atmosphere. Reference [51] studied the pollutants produced during the idle period when adding different percentages of EGR rates $(0,10,20,30 \%)$ to the suction 
manifold of a direct-injection diesel engine. The results of the study showed an increase in $\mathrm{CO}_{2}$ concentrations by increasing the time of idle period and engine idle speed, but it was not affected by injection timing. $\mathrm{CO}$ concentrations increased for all test conditions with the addition of EGR. $\mathrm{HC}$ concentrations increased with increasing idle period but decreased with increased idle speed and advancing the injection timing. NOx concentrations reduced by the addition of EGR and all variables studied from load and engine speed. Smoke is increased by increasing idle period and delaying the injection timing. When EGR is used, smoke is increased for all studied cases. The addition of EGR reduces engine noise for all tested conditions; noise was increased by increasing the time of idling and retarding the injection timing.

The addition of hydrogen to diesel has been studied in depth as a dual fuel and showed a significant increase in NOx concentrations. Reference [52] added EGR to dual fuel in a four-cylinder diesel engine and compared the effect of changing the equivalent ratio with the optimum injection timing at $1500 \mathrm{rpm}$ on performance and engine contaminants. The study results showed that the performance of the engine and the pollutants emitted from it are significantly affected by the studied variables. Adding a cooled EGR has a clear effect on the performance and engine contaminants. The results of the study showed that there is a mutual process between the addition of hydrogen and EGR. The addition of hydrogen causes an increase in NOx concentrations and decreases PM concentrations while cooled EGR reduces NOx concentrations and increases PM concentrations. The resulting NOx and PM concentrations are the result of these two factors. The study concluded that hydrogen should be considered as an alternative fuel to diesel engines due to the reduction of exhaust pollutants from burning it that can be further reduced using pollution control techniques such as EGR.

In the same vein, [53] studied the effect of the EGR on a diesel engine with a mixture of diesel - ethanol and diesel methanol where the added alcohol content was $10 \%$. The study focused on the mutual relationship between emitted PM and NOx. Results showed that PM concentrations decreased for the two mixtures and decreased with increased oxygen content in the mixture. The study showed a clear reduction for both PM and NOx using the studied system.

Reference [54] tested the performance of a direct injection diesel engine with a $10 \%$ diesel-methanol mixture with adding cooled and hot EGR. The study focused on the effect of operational variables such as the equivalence ratio, engine speed, load and injection timing. The results showed that combustion behavior of diesel-methanol mixtures differed from neat diesel. EGR addition reduces NOx concentrations. The addition of methanol to diesel has readjusted the negative effects of the recycling of exhaust gas on engine performance as the addition of methanol increases the oxygen available in the combustion chamber. The use of the cooled EGR results in better thermal efficiency, volumetric efficiency, reduced fuel consumption and better brake power than hot EGR. Engine performance improves with advancing injection timing when EGR is added.

\section{E. New ignition methods for diesel engines}

Experiments have proven that direct-injection diesel engines are efficient in all applications requiring these engines. However, because of the operating conditions of these engines, as it has high temperatures and high pressure during the burning fuel process that make these engines emit high pollutants levels, especially PM and NOx. So, researchers and designers around the world have developed new engine technologies that increase the efficiency of the diesel engine and reduce the time of PM and NOx pollutants. Iraqi researchers, like most researchers in the world, have studied this subject in detail and in many ways.

Reference [55] investigated the performance and emitted pollutants of $\mathrm{s}$ a partially-premixed combustion (PPC) concept that is supposed to emit fewer PM and NOx pollutants at the same time. The author used a mixture of gasoline-diesel with high levels of cooled EGR and early injection timing to increase ignition delay and give sufficient time for mixing air and fuel. The objective of the study was to examine the possibility of working the engine in PPC concept and the effect of this type of operation on the pollutants emitted and performance of the engine. The researcher used gasoline with $50 \%$ volume mixed with diesel and fixed engine speed of $1500 \mathrm{rpm}$. Cooled EGR was used that was left to pass through a heat exchanger designed to reduce the temperature of exhaust gas. Three high rates of EGR were used (30, 40 and 50\%). The use of the gasoline-diesel mixture has reduced the thermal efficiency of the engine and increased the fuel consumption compared to conventional diesel engine. The PPC engine causes a significant decrease in PM and NOx but the CO and $\mathrm{HC}$ concentrations increased significantly with a relative decrease in engine noise.

The use of Homogeneous Charge Compression Ignition (HCCI) engines can result in better performance and lower NOx concentrations due to the low temperatures resulting from high EGR presence. HCCI engines cause significant reductions in PM concentrations. Reference [56] studied this concept using a multi-cylinder diesel engine and adding EGR from $0 \%$ until the combustion misfire was occurred. The authors studied the effect of advancing injection timing to $35^{\circ} \mathrm{BTDC}$ and retarding it to $12^{\circ} \mathrm{BTDC}$ and compared it with the optimum timing for diesel fuel which is $17^{\circ} \mathrm{BTDC}$ for the used diesel fuel. The performance and contaminants of the HCCI engine have been compared with diesel engine alone and without the addition of EGR. The results showed that retarding injection timing caused a significant increase in fuel consumption up to $17 \%$. The thermal efficiency was reduced by $20.88 \%$. Advancing the injection timing with $50 \%$ of added EGR resulted in different results, as exhaust pollutants such as NOx, HC, PM, and engine noise significantly decreased compared to diesel engines. Increased EGR increases the concentrations of $\mathrm{CO}$ and $\mathrm{HC}$. The study concluded that the HCCI engine can be controlled by high rates of EGR and controlling the injection timing.

\section{IRAQI GASOLINE FUEL}

Iraqi gasoline is characterized by its average octane number of (80-85) with high sulfur content up to $0.5 \%$ in addition to high toxic lead compounds. This type of fuel 
causes knock conditions, which reduces its operational life. In addition, it releases harmful waste contaminants such as CO, NOx, and UBHC, as well as various PM types, PM2.5 and black soot. These engines also cause high noise. The pollutants emitted from single cylinder and multi-cylinder gasoline engines have been studied and found them very high compared to global standards. As these pollutants are high during the periods of idle and cold startup periods, which causes health and environmental problems for very large number of citizens, especially in the Respiratory system.

Reference [57] result indicated that the PM emitted from a multi-cylinder gasoline engine increases when it operates with lean or rich equivalence ratios, slow or fast speeds, when the engine's load is very small or large, and it increases when the spark timing significantly retarded or advanced. The lead compounds emitted from the engine increase with the increase of burning fuel, so it increases when switching from lean to rich equivalence ratios, increase the engine's speed, and increase its torque to high values. Lead compounds emitted levels are not affected by retarding or advancing the spark timing.

Reference [58] showed that the pollutants emitted from the gasoline engine during the cold operating period in the cold days of the city of Baghdad caused high air pollution rates. The levels of $\mathrm{HC}, \mathrm{CO}$ and $\mathrm{CO}_{2}$ depend on the amount of injected fuel. It also depends on the speed of the engine during this period and its length. NOx measurements showed unexpectedly high rates at $1000 \mathrm{rpm}$, and the lead pollutants were increasing at an accelerated rate, confirming the results of Reference [59]. The noise is reduced by increasing the engine speed during cold operation.

\section{A. The study of alternatives to gasoline}

Iraq is one of the countries with a high reservoirs of natural gas, most of which is not exploited. So many studies have focused on the operation of the engine with this gas or methane as it produced from NG [60]-[62]. Natural gas suffers from the problem of storage in vehicles as it takes a large volume with less distance to be cut compared to gasoline. It also gives lower power when working with the higher useful compression ratio (HUCR) of gasoline fuel which is $(8: 1)$, so this ratio should be increased to $14: 1$ to be suitable for the operation of the engine with natural gas and give the best performance. Pollutants emitted from natural gas combustion are significantly less than that produced by a gasoline engine.

Many researchers [63]-[67] have tried to use liquefied petroleum gas as fuel for a spark ignition engine as this gas is a derivative of oil products in refineries and in sufficient quantities to operate motor vehicles in Iraq. Liquefied petroleum gas (LPG) is characterized by its high resistance to knock and has higher octane number than gasoline and faster burning velocities. Therefore, the use of this gas is very appropriate. LPG emits more NOx levels than natural gas and gasoline. The rest of the hydrocarbon pollutants such as $\mathrm{CO}, \mathrm{HC}$, and $\mathrm{CO}_{2}$ are less than gasoline and higher than natural gas.

The researchers [68]-[72] attempted to use hydrogen gas as fuel for spark ignition engines and compared the performance and contaminants of a hydrogen engine to other hydrocarbon fuels (natural gas, LPG, and gasoline). Hydrogen has high volume due to its light molecular weight, which makes the quantities stored is little compared to the rest of the gases at a specific pressure. So, the pressure must be increased to increase the stored amount of hydrogen. The study of hydrogen as fuel in Iraq came from the fact that this gas can be produced from natural gas by liquefaction which became a very common and safe technique. The use of hydrogen as a fuel has become safe and has global experience that reached the stages of commercial use in vehicles recently.

The study of hydrogen as fuel for vehicles in Iraq is an advanced stage for Iraqi researchers. Studies have shown that hydrogen has the lowest energy level on the volume basis and the highest energy level on the weight basis. Hydrogen has a rapid burning velocity even higher than all known fuels globally. Burning hydrogen in internal combustion engines does not cause the production of hydrocarbon contaminants such as $\mathrm{CO}, \mathrm{HC}$, and $\mathrm{CO}_{2}$. Hydrogen combustion causes relatively high NOx emissions due to high temperatures resulting from the high flame propagation velocity. Hydrogen can be considered the cleanest fuel type that can be used in internal combustion engines and it is renewable fuel as it is produced from water and return to water after it is burned.

References [72]-[75] have practically studied the utility of mixing different types of gases with each other and the effect of the resulting fuel on the performance and the combustion pollutants. The addition of natural gas or methane, characterized by its low flame propagation compared to LPG, which reduces the flame propagation speed spread of the resulting fuel, and leads to reduce the resulting NOx levels compared to the LPG engine. However, this mixture causes an underestimation of engine performance and the need to advance the optimum spark timing. On the contrary, the addition of hydrogen to the liquefied petroleum gas caused the flame propagation speed to increase and improve the performance of the engine depending on the proportion of volume fraction of hydrogen added. When the hydrogen fraction in the mixture becomes higher than $70 \%$, it causes a decrease in engine performance because of the large reduction in the volumetric efficiency.

Hydrocarbon emissions from a hydrogen-fired LPG engine are less than LPG burning alone. The emitted NOx increases because of the faster spread of flame generated by the hydrogen addition, which causes high pressure and temperatures in the combustion chamber. Adding hydrogen to both NG and LPG improves combustion specifications, reduces hydrocarbon contaminants and increases NOx emissions.

Reference [76] studied the lean limit specification for various types of fuel used in spark ignition engines and found that hydrogen has the longest range of equivalence ratios, and works at very low equivalence rates that cannot be reached in any other fuel. Reference [77] has studied the addition of hydrogen to gasoline on the performance of a spark ignition engine. This addition greatly improves the flame propagation speed, which improves the performance of the engine and reduces the fuel consumption if the addition of hydrogen at a small volume fractions. When the hydrogen fractions were increased the volumetric efficiency 
degraded that reduces the performance of the engine. The unique hydrogen specifications make it more efficient to use in spark ignition engines and lower exhaust emissions except for NOx which can be treated by many techniques [78].

\section{B. The addition of liquid fuels to gasoline}

The addition of different types of alcohols such as ethanol and methanol is a globally acceptable experience, but even more, engines that work with these types of fuel are available and operating in Brazil and some countries of Europe and the United States of America. Ethanol and methanol are two of the most widely used substances. These two substances have a proportion of oxygen in their internal composition, which makes their combustion cleaner and gives less exhaust pollutants. The availability of oxygen is one of the conditions of high NOx emissions from the engine in addition to the high temperature of the combustion chamber. This is also available as oxygenates give high combustion temperatures when added to gasoline, causing NOx rise [79].

Reference [80] added ethanol to gasoline at volume fractions of $10 \%$ and $20 \%$, and studied the effect of this addition on engine performance and pollutants. The results showed that the addition of ethanol to gasoline fuel can increase the useful compression ratio from 8: 1 in the case of gasoline alone to 9.5: 1, which results in better performance of the engine, increasing the engine's brake power. In the case of the addition of ethanol to the gasoline, the specific consumption increases by about $10 \%$ due to the lower heating value of the fuel compared with the gasoline, and the $\mathrm{CO}$ and $\mathrm{CO}_{2}$ pollutants are significantly reduced.

Reference [81] studied the use of a three-component mixture (ternary mixture) consisting of gasoline, ethanol and methanol as an alternative to conventional Iraqi gasoline. The study used an equal GEM mixture in the octane classification of the E85 mixture. The selected mixture was G37 E20 M43 (37\% gasoline $+20 \%$ ethanol $+43 \%$ methanol) in the study. The use of this mixture in a multicylinder spark ignition engine and the performance of the engine and the pollutants emitted by the gasoline engine were investigated. The results showed that the materials of this mixture are available in Iraq, and this mixture has significant benefits when compared to its gasoline engine. The higher useful compression ratio was increased to 9.25: 1, whereas for gasoline it was 7.5: 1. GEM engine power increased by $24.12 \%$, the specific fuel consumption decreased by $13.9 \%$, and the thermal and volumetric efficiencies increased by $19.59 \%$ and $8.06 \%$ respectively. Concentrations of $\mathrm{CO}$ and $\mathrm{HC}$ pollutants were reduced by 30.5 and $25.16 \%$, respectively. The smoke was reduced by $46.49 \%$ and the $\mathrm{CO}_{2}$ concentrations decreased by $5 \%$ while the NOx concentrations decreased by $1.75 \%$. The study proved that the proposed fuel has environmental benefits and also increases engine performance.

Reference [82] studied the effect of different percentages of ethanol added to gasoline $(20,50 \& 80 \%)$ on PM and lead compounds produced by the engine and compared to those emitted when using Iraqi gasoline. The results of the study showed a decrease in PM by increasing the proportion of ethanol in the mixture to 50 and $80 \%$. The proportion of lead compounds emitted decreased by the same volume as the added ethanol fraction. The study has shown that the addition of ethanol reduces these two undesirable types of pollutants significantly.

Reference [83] chose to study several types of fuel and their effects on emissions emitted during the idle period. The researchers selected three types of available fuels in Iraq: standard octane gasoline 82 , excellent octane 92, M20 ( $20 \%$ methanol and $80 \%$ gasoline). The results showed that the operation of the engine at high idle speed emits high levels of $\mathrm{CO}, \mathrm{CO}_{2}, \mathrm{HC}, \mathrm{NOx}$ and noise. The resulting emission levels depend largely on the fuel type. Super gasoline $(\mathrm{ON}=92)$ showed a lower emission levels except for noise for each tested idle speed. The addition of methanol to normal gasoline $(\mathrm{ON}=82)$ resulted in high levels of $\mathrm{CO}, \mathrm{CO}_{2}, \mathrm{HC}$ emitted in comparison with excellent gasoline. Nitrogen oxides emissions were close to zero for most idle speeds and for all the studied fuels.

\section{The laminar flame spread studies}

The laminar flame speed of any air-fuel mixture is a characteristic of the fuel, where each type of fuel has its own speed that varies from fuel to another. Although fuel is mixed into the combustion chamber with the air in a turbulent movement as the piston rises from the bottom dead center to the top dead center, researchers often study the laminar flame burning velocity, which is what most Iraqi researchers have relied on. The measurement of flame propagation speed is measured in several different ways, each with its accuracy and determinants.

Reference [84] measured the laminar burning velocity and flame spread practically for a wide range of equivalent ratios of hydrogen-air mixture (from $\varnothing=0.2$ to 1.7 ). The researcher used for this purpose a fixed-size vessel and thermocouple method at normal temperature and pressure $\left(25^{\circ} \mathrm{C}\right.$ and 1 bar). He also studied the length of Markstein, which expresses the sensitivity of the laminar burning velocity to the rate of flame expansion. Markstein is another characteristic of the class combustion that can be estimated from instantaneous practical measurements. Markstein lengths reflect changes in the speed of the local flame due to external elongation, which are important in expressing the onset of flame instability, stretch rate and extinguishing the flame. The results of the study showed that the radius of the flame increases with time, but the increase rate decreases with the flame spread at the lean equivalent ratios. At rich equivalent ratios, there is almost a linear relationship between the radius of the flame and the time. At ideal equivalence ratios, combustion shows a linear relationship between the flame radius and time. The flame propagation speed increases with an increase in the equivalent ratio, and the Markstein number increases, indicating an improvement in flame stability, which is also improved by increasing the equivalent ratio. The researchers compared the results of their practical study with literature that gave a clear and acceptable affinity [85].

The importance of hydrogen as a fuel or as an added fuel due to its properties in increasing the flame spread, Reference [86] has studied the laminar flame burning velocity and the Markstein number for various volume fractions of hydrogen to natural gas (from 0 to 100\%) and 
for variable equivalence ratios (from 0.2 to 1.7 ). The results showed that the flame speed of the mixture increases with a nonlinear relationship with the increase of the hydrogen content at lean equivalence ratios, the relationship was linear at the stoichiometric equivalence ratios, and the near-linear relationship of the rich equivalence ratios. As for the Markstein length, it is reduced, and the instability of the flame increases by enriching the fuel with hydrogen. If a specific amount of hydrogen is added, the Markstein number increases and the flame stability increases with increasing the equivalence ratio.

Reference [87] used the thermocouples method to measure the flame propagation velocity of a mixture of LPG and hydrogen. The speed of the spread of stretched flame is obtained by linear induction when the flame stretching equals is zero. The length of Markstein was measured from the linear relationship between the flame velocity and the stretch rate. The study showed that the burning speed of the LPG flames increased with the addition of hydrogen volume fraction. The Markstein length showed the lack of stability of the flame when adding hydrogen. The results also showed that the addition of hydrogen increases the equivalence ratio range that the mixture can work on both at the lean and the rich sides.

Reference [88] studied the laminar flame burning velocity and Markstein lengths for diesel-oxygenates mixtures like (methanol, ethanol, bio-diesel from sunflower oil, and used vegetable oils) pre-blended with air. A central ignition was used with a constant volume of ballast expansion with thermocouples connected to data acquisition system. In this study, the unstable flame burning velocity, Markstein length, Lewis number, Zoldevich number and Karlovic number, was measured for a wide range of equivalencies $(\varnothing$ from 0.2 to 1.4 ). The study showed that the flame burning velocity of tested diesel-oxygenates mixtures, is clearly different, because of the molecular structure which has a significant impact on the flame spread for each fuel. The fastest measured spread of the studied mixtures flame were at equivalence ratios close to $(\varnothing=1.1)$. Markstein length was reduced with increasing the equivalence ratio of air-fuel mixtures, which means that the stability of the flame increases. The highest values for the Zoldvich number were reached at the stoichiometric equivalence ratio $(\varnothing=1.0)$. The results show that Markstein lengths are relatively independent of Karlovic numbers.

The speed of flame propagation is very important in combustion modeling and in ensuring design and improvement, so practical measurements are required. Reference [89] used the ballistic flare technique at constant pressure, because it is possible to use high initial pressure and temperature conditions. The researchers studied the velocity of the flame propagation of propane-air mixtures to the point of practical information available in this regard at various initial pressures and temperatures. The flame propagation velocity was studied at a wide range of equivalent ratios from $\varnothing=0.5$ to $\varnothing=1.5$. The study was conducted at initial temperatures of 300 to $350 \mathrm{~K}$ and for initial mixture pressures from 0.5 to 1.5 bar. The study showed that the highest flame speed can be obtained at relatively rich rates and at high initial temperatures, which was validated by Reference [90]. When the initial pressure is increased, the flame speed is reduced. Markstein number increased for the burned mixture by increasing the equivalence ratio of the mixture and increasing its primary temperature [91].

\section{The use of exhaust gas recirculation (EGR) to minimize gasoline engine contaminants}

The use of exhaust gas recirculation as an effective method to reduce NOx contaminants in the exhaust was studied in Iraq. As the reactant gases generated by the combustion will absorb part of the heat of the combustion chamber, thereby reducing the maximum combustion temperature and as a result less interaction between oxygen and nitrogen that reduces the NOx pollutants. Reference [92] used this technique for a fuel composed of adding methanol alcohol to Iraqi gasoline by $20 \%$ (M20). In this study, a single cylinder engine that can control the speed, load, sparks timing and the equivalent ratio and can also change the compression ratio of the engine was used. Measurements were performed at variable speeds and loads at stoichiometric equivalent ratio and optimum spark timing with the addition of $20 \%$ of a recirculated exhaust gas to the intake manifold. The results showed that the higher useful compression ratio of the M20 mixture decreased from 9.5: 1 to 9.0: 1 when adding EGR. The use of M20 alone resulted in an increase in engine brake power up to $6 \%$ and reduced the specific fuel consumption up to $3 \%$ compared to the fuel of the engine with Iraqi gasoline. The addition of the EGR to the M20 caused a reduction in the higher compression ratio and the optimum spark timing of the engine, as well as the increase in the specific fuel consumption, reducing the thermal efficiency, volumetric efficiency, and exhaust gas temperatures.

EGR has different effects on the engine performance, combustion and emitted contaminants that are difficult to distinguish, [93] has studied the knock phenomenon of associated with of a single-cylinder spark ignition engine works under high-load operation conditions at the higher useful compression ratio for the fuels used and the addition of cooled EGR. The researcher used natural gas, liquefied petroleum gas, and hydrogen as fuels. The results showed that the intensity of the engine knock decreased significantly with the addition of cooled EGR and the decrease in the knock phenomenon depends on the mass of the recirculated exhaust gas. The knock phenomenon for the studied fuels can be prevented by working at low equivalent ratios, reducing the compression ratio, and retarding the spark timing. The addition of cool EGR to the intake manifold reduced the temperature of the cylinder at the end of the compression stroke, which definitely reduces knock access.

Iraq's bioethanol is a suitable alternative to gasoline as it reduces the hydrocarbon pollutants emitted from internal combustion engines because of the high proportion of oxygen in its internal structure. Reference [94] devoted a study to examine the effect of adding an EGR to Iraqi gasoline mixed with 10 and $20 \%$ bioethanol in addition to $10 \%$ of the hot and cooled EGR. Experimental work has been done on a multi-cylinder spark ignition engine at variable torque, speed and spark timing conditions. The results of the study showed that the addition of bio-ethanol to gasoline reduced the smoke opacity and NOx levels, and 
this effect depends on the mixing rate according to a certain pattern. The addition of EGR causes increased smoke and limited the reduction rate of opacity due to the addition of ethanol. The addition of a cooled EGR caused a reduction in NOx concentrations with high smoke emission. Retarding spark timing increased the smoke opacity and significantly reduces NOx concentrations. Advancing spark timing increased NOx concentrations and reduces smoke opacity.

Reference [95] used hydrogen as a fuel in a spark ignition engine. The use of hydrogen as a fuel represents some challenges as the abnormal combustion phenomenon like back-fire, pre-ignition, and knocks, which the author discussed, in addition to the high emitted NOx levels from hydrogen engine. The author used EGR to reduce NOx, and pumping loss. EGR use has some disadvantages like its negative impact on combustion stability. Two separate hot and cooled EGR systems were used. The study indicated that adding EGR reduced the combustion temperature in the combustion chamber. This reduction caused lower NOx emissions, and eliminates the abnormal combustion of hydrogen.

\section{E. New ignition methods for SI engines}

Improving engine performance and reducing its pollution is a constant concern for designers and engineers, including Iraqi researchers. In this effort, Reference [96] has examined the effect of the overlap period variation and focused on the effect of changing valves timing on the performance of the engine and the pollutants emitted from it. Experiments on changing valve timing were performed on a single cylinder drive by changing the clearance distance between the rocker arm and valve stem. The study results showed that at compression ratio of 9: 1 and overlap $=104^{\circ}$, the best performance was achieved with the lowest exhaust pollutants, increasing thermal efficiency and volumetric efficiency up to $5.65 \%$ and $12.58 \%$, respectively. The specific fuel consumption was reduced by $3 \%$, while $\mathrm{HC}$ and CO pollutants were reduced to $4.45 \%$ and $20.19 \%$, respectively.

\section{CONCLUSIONS}

Many alternative fuels for gasoline and diesel in Iraq have been extensively studied. The researcher has worked very hard to explore the possibility of using multiple types of alternative fuels available locally at the commercial level without adding a cost or low cost to the consumer. The availability of multiple types of alternative fuel makes its use possible.

Iraq can produce biofuels in large quantities as this country is an agricultural country and biofuels are an effective alternative to gasoline and diesel. The approach to alternative fuels needs a decision and a political will to change the environmental reality of the country. Citizens and the environment in Iraq are waiting for their officials to take important steps in order to reduce air pollution and improve the health conditions by switching to alternative fuels.

\section{REFERENCES}

[1] M. T. Chaichan and K. A. H. Al-Asadi, "Environmental impact assessment of traffic in Oman," International Journal of Scientific \& Engineering Research, vol. 6, no. 7, pp. 493-496, 2015

[2] H. M. S. Al-Maamary, H. A. Kazem, M. T. Chaichan, "Changing the energy profile of the GCC States: A review," International Journal of
Applied Engineering Research (IJAER), vol. 11, no. 3, pp. 1980-1988, 2016.

[3] H. M. S. Al-Maamary S, H. A. Kazem, M. T. Chaichan, "Climate change: the game changer in the GCC region," Renewable and Sustainable Energy Reviews, vol. 76, pp. 555-576, 2017. http://dx.doi.org/10.1016/j.rser.2017.03.048

[4] H. M. S. Al-Maamary, H. A. Kazem, M. T. Chaichan, "Renewable energy and GCC States energy challenges in the 21st century: A review," International Journal of Computation and Applied Sciences IJOCAAS, vol.2, no. 1, pp. 11-18, 2017.

[5] M. T. Chaichan \& H. A. Kazem, "Thermal storage comparison for variable basement kinds of a solar chimney prototype in Baghdad Iraq weathers," International journal of Applied Science (IJAS), vol.2, no. 2, pp. 12-20, 2011

[6] M. T. Chaichan, "Practical study of basement kind effect on solar chimney air temperature in Baghdad-Iraq weather." Al Khwarizmi Eng. Journal, vol. 7, no. 1, pp. 30-38, 2011.

[7] Ahmed S T \& M. T. Chaichan, "A study of free convection in a solar chimney sample," Engineering and Technology J, vol. 29, no. 14, pp. 2986-2997, 2011.

[8] M. T. Chaichan \& K. I. Abaas, "Practical investigation for improving concentrating solar power stations efficiency in Iraqi weathers," Anbar J for Engineering Science, vol.5, no. 1, pp. 76-87, 2012.

[9] H. A. Kazem, Aljibori H S, Hasoon F N and M. T. Chaichan, "Design and testing of solar water heaters with its calculation of energy," Int. J. of Mechanical Computational and Manufacturing Research, vol. 1. no.2, pp. 62-66, 2012

[10] M. T. Chaichan, K. I. Abaas \& H. A. Kazem, "The effect of variable designs of the central receiver to improve the solar tower efficiency," International J of Engineering and Science, vol. 1, no. 7, pp. 56-61, 2012.

[11] M. T. Chaichan \& K. I. Abaas, "Productivity amelioration of solar water distillator linked with salt gradient pond," Tikrit Journal of Engineering Sciences, vol. 19, no. 4, pp. 24-34, 2012.

[12] M. T. Chaichan, Abaas K I, H. A. Kazem, Hasoon F, Aljibori H S, Alwaeli A A K and Alwaeli A H A, "Effect of design variation on saved energy of concentrating solar power prototype," Proceedings of the World Congress on Engineering (WCE 2012), Vol. III, July 4 - 6, London, UK, 2012.

[13] M. T. Chaichan \& K. I. Abaas, "Productivity amelioration of solar water distillator linked with salt gradient pond," Tikrit Journal of Engineering Sciences, vol. 19, no. 4, pp. 24-34, 2012.

[14] M. T. Chaichan, K. I. Abaas, F. F. Hatem, "Experimental study of water heating salt gradient solar pond performance in Iraq," Industrial Applications of Energy Systems (IAESO9), Sohar University, Oman, 2009.

[15] M. T. Chaichan, K. I. Abaas, "Performance amelioration of a Trombe wall by using phase change material (PCM)," International Advanced Research Journal in Science, Engineering and Technology, vol. 2, no. 4, pp. 1-6, 2015.

[16] M. T. Chaichan, A. H. Al-Hamdani, A. M. Kasem, "Enhancing a Trombe wall charging and discharging processes by adding nano- $\mathrm{Al}_{2} \mathrm{O}_{3}$ to phase change materials," International Journal of Scientific \& Engineering Research, vol. 7, no. 3, pp. 736-741, 2016.

[17] M. T. Chaichan, K. I. Abaas, D. S. M. Al-Zubidi, "A study of a hybrid solar heat storage wall (Trombe wall) utilizing paraffin wax and water," Journal of Research in Mechanical Engineering, vol. 2, no. 11 , pp. 1-7, 2016.

[18] M. T. Chaichan, K. I. Abaas, D. S. M. Al-Zubidi, H. A. Kazem, "Practical investigation of effectiveness of direct solar-powered air heater," International Journal of Advanced Engineering, Management and Science (IJAEMS), vol. 2, no. 7, pp:1047-1053, 2016.

[19] M. T. Chaichan, K. I. Abaas, M. A. Rasheed and H. A. Kazem, "Using paraffin wax as a thermal storage material in a solar air heater," International Conference for Renewable Energies, University of Technology, Baghdad, Iraq, 2013.

[20] M. T. Chaichan, B. A. Mohammed and H. A. Kazem, "Effect of pollution and cleaning on photovoltaic performance based on experimental study," International Journal of Scientific and Engineering Research, vol. 6, no. 4, pp: 594-601, 2015.

[21] Z. A. Darwish, H. A. Kazem, K. Sopian K, M. A. Alghoul and M. T. Chaichan, "Impact of some environmental variables with dust on solar photovoltaic (PV) performance: Review and research status," International $J$ of Energy and Environment, vol. 7, no. 4, 152-159, 2013.

[22] M. T. Chaichan, H. A. Kazem, "Experimental analysis of solar intensity on photovoltaic in hot and humid weather conditions," International Journal of Scientific \& Engineering Research, vol. 7, no. 3, 91-96, 2016. 
[23] A. A. Alwaely, H. N. Al-qaralocy, K. A. Al-Asadi, M. T. Chaichan, H. A. Kazem, "The environmental aftermath resulted from chemica bombardment of Halabja Territory for the period 1988-2014," International Journal of Scientific \& Engineering Research, vol. 6 , no. 9, pp. 40-44, 2015

[24] B. R. Yaseen, K. A. Al Asaady, A. A. Kazem, M. T. Chaichan, "Environmental impacts of salt tide in Shatt al-Arab-Basra/Iraq," IOSR Journal of Environmental Science, Toxicology and Food Technology, vol. 10, no. 1-2, 35-43, 2016.

[25] A. A. Kazem, M. T. Chaichan \& H. A. Kazem, "Effect of dust on photovoltaic utilization in Iraq: review article," Renewable and Sustainable Energy Reviews, vol. 37, September, pp. 734-749, 2014.

[26] M. T. Chaichan \& H. A. Kazem, "Status and future prospects of renewable energy in Iraq," Renewable and Sustainable Energy Reviews, vol. 16, no. 1, pp. 6007-6012, 2012

[27] A. A. Al-Waeely, S. D. Salman, W. K. Abdol-Reza, M. T. Chaichan, H. A. Kazem and H. S. Al-Jibori, "Evaluation of the spatia distribution of shared electrical generators and their environmental effects at Al-Sader City-Baghdad-Iraq," International Journal of Engineering \& Technology IJET-IJENS, vol. 14, no. 2, pp. 16-23, 2014.

[28] M. T. Chaichan, H. A. Kazem, T. A. Abid, "The environmental impact of transportation in Baghdad, Iraq," Environment Development and Sustainability, 2016. DOI: 10.1007/s10668-0169900-x.

[29] M. T. Chaichan, "Practical study of performance of compression ignition engine fueled with mixture of diesel fuel and ethanol," Proceeding to the third International conference on modeling, simulation and applied optimization (ICMSAO'09), Al-Sharija, UAE 2009.

[30] M. T. Chaichan \& A. M. Saleh, "Study of compression ignition engine performance when fueled with mixtures of diesel fuel and alcohols," Association of Arab Universities Journal of Engineering Science, vol. 17, no.1, pp. 1-22, 2010.

[31] M. T. Chaichan, "Emissions and performance characteristics of ethanol-diesel blends in CI engines," Engineering and Technology $\mathrm{J}$, vol. 28, no. 21, pp. 6365-6383, 2010

[32] M. T. Chaichan \& K. I. Abaas, "Emissions characteristics of methanol-diesel blends in CI engines," Wassit Journal for Science \& Medicine, vol. 5, no.1, pp. 177-189, 2012

[33] S. T. Ahmed \& M. T. Chaichan, "Effect of fuel cetane number on multi-cylinders direct injection diesel engine performance and emissions," Al-Khwarizmi Eng. Journal, vol. 8, no.1, pp. 65-75, 2012.

[34] K. J. Al-Khishali, A. M. Saleh, H. Mohammed, M. T. Chaichan, "Experimental and CFD simulation for Iraqi diesel fuel combustion," 1st International Babylon Conference, Babylon, Iraq, 2015.

[35] M. T. Chaichan, "Exhaust analysis and performance of a single cylinder diesel engine run on dual fuels mode," Baghdad Engineering Collage Journal, vol. 17, no. 4, pp. 873-885, 2011.

[36] M. T. Chaichan and A. M. Saleh, "Practical investigation of performance of single cylinder compression ignition engine fueled with duel fuel," The Iraqi Journal for Mechanical and Material Engineering, vol. 13, no. 2, pp. 198-211, 2013.

[37] M. T. Chaichan, D. S. M. Al-Zubaidi, "A practical study of using hydrogen in dual - fuel compression ignition engine," International Journal of Mechanical Engineering (IIJME), vol.2, no. 11, pp. 1-10, 2014

[38] M. T. Chaichan, "Combustion of dual fuel type natural gas/liquid diesel fuel in compression ignition engine," Journal of Mechanical and Civil Engineering (IOSR JMCE), vol. 11, no. 6, pp. 48-58, 2014.

[39] M. T. Chaichan, D. S. M. Al-Zubaidi, "Operational parameter influence on resulted noise of multi-cylinders engine runs on dua fuels mode," Journal of Al-Rafidain University Collage for Science vol. 35, pp. 186-204, 2014

[40] M. T. Chaichan, "The effects of hydrogen addition to diesel fuel on the emitted particulate matters," International Journal of Scientific \& Engineering Research, vol. 6, No. 6, pp. 1081-1087, 2015

[41] M. T. Chaichan, O. K. Maroon, K. I. Abaas, "The effect of diese engine cold start period on the emitted emissions," International Journal of Scientific \& Engineering Research, vol. 7, no. 3, pp. 749753,2016

[42] M. T. Chaichan, Effect of injection timing and coolant temperatures of DI diesel engine on cold and hot engine startability and emissions, IOSR Journal of Mechanical and Civil Engineering (IOSRJMCE), vol. 13, No. 3-6, pp. 62-70, 2016.

[43] M. T. Chaichan, "Practical investigation of the performance and emission characteristics of DI compression ignition engine using water diesel emulsion as fuel," Al-Rafidain Engineering Journal, vol 21, no. 4, pp. 29-41, 2013.
[44] M. T. Chaichan \& S. T. Ahmed, "Evaluation of performance and emissions characteristics for compression ignition engine operated with disposal yellow grease," International Journal of Engineering and Science, vol.2, no. 2, pp. 111-122, 2013.

[45] M. T. Chaichan \& D. S. Al Zubaidi, "Practical study of performance and emissions of diesel engine using biodiesel fuels," Association of Arab Universities Journal of Engineering Science, vol. 18, no. 1, pp. 43-56, 2012.

[46] M. T. Chaichan, "Performance and emission study of diesel engine using sunflowers oil-based biodiesel fuels," International Journal of Scientific and Engineering Research, vol. 6, no. 4, pp. 260-269, 2015.

[47] M. T. Chaichan, "Evaluation of emitted particulate matters emissions in multi-cylinder diesel engine fuelled with biodiesel," American Journal of Mechanical Engineering, vol. 4, no. 1, pp. 1-6, 2016.

[48] M. T. Chaichan \& A. M. Saleh, "Practical investigation of the effect of EGR on DI multi cylinders diesel engine emissions," Anbar Journal for Engineering Science (AJES), vol. 6, No. 3, pp. 401-410, 2013.

[49] M. T. Chaichan, K. I. Abaas \& A. H. Naser, "Study of the effect of exhaust gas recirculation on performance and emitted noise of an engine fueled with diesel fuel," Association of Arab Universities Journal of Engineering Science, vol. 20, no. 1, pp. 43-59, 2013.

[50] M. T. Chaichan, A. Q. Salam \& AS. A. bdul-Aziz, "Impact of EGR on engine performance and emissions for CIE fueled with dieselethanol blends," Arabic universities Union Journal, vol. 27, no. 2 2014.

[51] M. T. Chaichan, "Exhaust gas recirculation (EGR) and injection timing effect on emitted emissions at idle period," Al-Khwarizmi Engineering Journal, vol.10, no. 4, pp. 33-44, 2014

[52] M. T. Chaichan, "The impact of equivalence ratio on performance and emissions of a hydrogen-diesel dual fuel engine with cooled exhaust gas recirculation," International Journal of Scientific \& Engineering Research, vol. 6, no. 6, pp. 938-941, June-2015.

[53] M. T. Chaichan, "Improvement of NOx-PM trade-off in CIE though blends of ethanol or methanol and EGR," International Advanced Research Journal in Science, Engineering and Technology, vol. 2, no. 12, pp. 121-128, 2015.

[54] M. T. Chaichan, Q. A. Abass, "Effect of cool and hot EGR on performance of multi-cylinder CIE fueled with blends of diesel and methanol," Al-Nahrain Collage of Engineering Journal, vol. 19, no. 1, pp. 76-85, 2016

[55] M. T. Chaichan, "Combustion and emissions characteristics for DI diesel engine run by partially-premixed (PPCI) low temperature combustion (LTC) mode," International Journal of Mechanical Engineering (IIJME), vol. 2, no. 10, pp. 7-16, 2014.

[56] M. T. Chaichan, K. I. Abaas, "EGR and injection timing variation effects of an engine run in HCCI mode performance and emitted emissions," International Journal of Engineering Trends and Technology (IJETT), vol. 19, no. 3, pp. 120-130, 2015

[57] M. T. Chaichan, "Experimental evaluation of the effect of some engine variables on emitted $\mathrm{PM}$ and $\mathrm{Pb}$ for single cylinder SIE," Association of Arab Universities Journal of Engineering Science, vol. 2, no. 20, pp. 1-13, 2013

[58] M. T. Chaichan, O. K. Marhoon, B. A. Mohammed, "The effect of spark ignition engine cold starting period on the emitted emissions," Scientific and Eng. Reports, vol. 1, no.1, pp. 1-8, 2016. DOI: 10.18282/ser.v1.i1.40

[59] M. T. Chaichan \& S. A. Al Sheikh, "Study of SIE performance fueled with methane," Al-Jufra University Journal, vol.1, no.1, pp. 15-27, 2001

[60] M. T. Chaichan \& S. Al Sheikh, "Study of, NOx and CO emissions for SIE fueled with methane," proceeding to International Conference for Energy and Environment, Brack, Libya, 2003

[61] M. T. Chaichan, J. A. Kadhum, K. S. Riza, "Spark ignition engine performance when fueled with NG, LPG and gasoline," Saudi Journal of Engineering and Technology, vol. 1, no. 3, pp. 105-116, 2016. DOI: $10.21276 /$ sjeat.2016.1.3.7

[62] A. A. Salim \& M. T. Chaichan, "Study of SIE performance fueled with LPG," Sabha University Journal, vol.4, no. 4, pp. 67-82, 2003.

[63] A. A. Salim \& M. T. Chaichan, "Study of NOx and CO emissions for SIE fueled with LPG," Sabha University Journal, vol.1, no.1, pp. 106- 125,2002

[64] M. T. Chaichan, "Study of NOx and CO emissions for SIE fueled with Supplementary methane to LPG," The Iraqi Journal for Mechanical and Material Engineering, vol.6, no.2, pp. 85-97, 2006.

[65] M. T. Chaichan, "Study of NOx and CO emissions for SIE fueled with different kinds of hydrocarbon fuels," Association of Arab Universities Journal of Engineering Science, vol.13, no. 2, pp. 85$105,2006$. 
[66] M. T. Chaichan, "Study of performance of SIE fueled with different kinds of hydrocarbon fuels," Association of Arab Universities Journal of Engineering Science, vol.14, no.1, pp. 25-44, 2007.

[67] A. A. Salim \& M. T. Chaichan, "Study of SIE performance fueled with hydrogen," Sabha University Journal, vol.6, No .3, pp. 32-57, 2004.

[68] M. T. Chaichan, "Practical study of compression ratio, spark timing and equivalence ratio effects on SIE fueled with hydrogen." Proceeding to Industrial Applications of Energy Systems, Sohar University, Oman, 2008.

[69] M. T. Chaichan and Q. A. Abaas, "Study of NOx emissions of SI engine fueled with different kinds of hydrocarbon fuels and hydrogen," Al Khwarizmi Eng. Journal, vol. 6, no. 2, pp. 11-20, 2010.

[70] M. T. Chaichan and A. M. Saleh, "Practical investigation of single cylinder SI Engine performance operated with various hydrocarbon fuels and hydrogen," Al Mostanseria Journal for engineering and development, vol. 14, no. 2, pp. 183-197, 2010.

[71] M. T. Chaichan and K. I. Abaas, "Experimental comparison of CO emissions emitted from single cylinder S I engine fueled with different kinds of hydrocarbon fuels and hydrogen," Iraqi Journal for Mechanical and Material Eng., vol. 10, no. 3, pp. 397-405, 2010.

[72] M. T. Chaichan, "Study of performance of SIE fueled with supplementary methane to LPG," The Iraqi Journal for Mechanical and Material Engineering, vol.7, no.4, pp. 25-44, 2007.

[73] M. T. Chaichan, "Spark ignition engine performance fueled with hydrogen enriched liquefied petroleum gas (LPG)," Scholars Bulletin Journal, vol. 2, no. 9, pp. 537-546, 2016.

[74] M. T. Chaichan, "Study of performance of SIE fueled with Supplementary hydrogen to LPG," Association of Arab Universities Journal of Engineering Science, vol.16, no.1, pp. 125-145, 2009.

[75] M. T. Chaichan, "Study of NOx and CO emissions for SIE fueled with Supplementary hydrogen to LPG," Association of Arab Universities Journal of Engineering Science, vol. 16, no.2, pp. 32-47, 2009.

[76] M. T. Chaichan, "Characterization of lean misfire limits of alternative gaseous fuels used for spark ignition engines," Tikrit Journal of Engineering Sciences, vol.19, no.1, pp. 50-61, 2012.

[77] M. T. Chaichan, "Study of performance of SIE fueled with Supplementary hydrogen to gasoline," Baghdad Engineering Collage Journal, vol.12, no.4, pp. 983-996, 2006.

[78] M. T. Chaichan, "Study of NOx and CO emissions for SIE fueled with Supplementary hydrogen to gasoline," Baghdad Engineering Collage Journal, vol. 16, no. 1, pp. 4606-4617, 2010.

[79] M. T. Chaichan \& K. I. Abaas, "Emissions characteristics of methanol-diesel blends in CI engines," Wassit Journal for Science \& Medicine, vol. 5, no.1, pp. 177-189, 2012.

[80] A. M. Saleh and M. T. Chaichan, "The effect of alcohol addition on the performance and emission of single cylinder spark ignition engine," proceeding to Najaf Technical collage international scientific conference, Najaf, Iraq, 2010.

[81] M. T. Chaichan, "GEM Ternary blends utilization as an alternative to conventional Iraqi gasoline to suppress emitted sulfur and lead components to environment," Al-Khwarizmi Journal, vol. 12, no. 3, pp. 38-51, 2016

[82] M. T. Chaichan, "The impact of engine operating variables on emitted $\mathrm{PM}$ and $\mathrm{Pb}$ for an SIE fueled with variable ethanol-Iraqi gasoline blends," IOSR Journal of Mechanical and Civil Engineering (IOSRJMCE), vol. 12, no. 6-1, pp. 72-79, 2015.
[83] M. T. Chaichan, K. I. Abaas, B. A. Mohammed, "Experimental study of the effect of fuel type on the emitted emissions from SIE at idle period," Al-Khwarizmi Engineering Journal, vol. 13, No.1, pp. 1-12, 2017.

[84] M. T. Chaichan, "Practical measurements of laminar burning velocities for hydrogen-air mixtures using thermocouples," Association of Arab Universities Journal of Engineering Science, vol 17, no. 2, 2010.

[85] M. T. Chaichan \& A. M. Saleh, "Experimental measurements of laminar burning velocities and Markstein number of hydrogen-air mixtures," The 3rd Scientific International Conference, Technical College, Najaf, Iraq, 2013

[86] M. T. Chaichan, "The measurement of laminar burning velocities and Markstein numbers for hydrogen enriched natural gas," International Journal of Mechanical Engineering \& Technology (IJMET), vol. 4, no. 6, pp. 110-121, November- December, 2013.

[87] M. T. Chaichan, "Measurements of laminar burning velocities and Markstein length for LPG-hydrogen-air mixtures," International Journal of Engineering Research and Development, vol. 9, no. 3, 2013.

[88] M. T. Chaichan, "Practical measurements of laminar burning velocities and Markstein Numbers for Iraqi diesel-oxygenates blends," The Iraqi Journal for Mechanical and Material Engineering, vol. 13, no. 2, pp. 289-306, 2013.

[89] A. M. Saleh \& M. T. Chaichan, "The effect of initial pressure and temperature upon the laminar burning velocity and flame stability for propane-air mixtures," Global Advanced Research Journal of Engineering, Technology and Innovation, vol. 3, no. 7, pp. 154-201, 2014

[90] A. M. Saleh, M. T. Chaichan, A. H. Naser, "Study of the effect of elevated temperatures on the laminar burning velocity of propane-air mixtures," The 2nd Scientific Conference of Engineering Science, Diyala, Iraq, 2015.

[91] A. M. Saleh, M. T. Chaichan, A. M. J. Mahdy, "Study of the effect of elevated pressures on the laminar burning velocity of propane-air mixtures," The 2nd Scientific Conference of Engineering Science, Diyala, Iraq, 2015.

[92] M. T. Chaichan, "EGR effect on performance of a spark ignition engine fueled with blend of methanol-gasoline," Wassit Journal of Engineering Science, vol. 1, no. 2, pp. 93-110, 2013.

[93] M. T. Chaichan, "Evaluation of the effect of cooled EGR on knock of SI engine fueled with alternative gaseous fuels," Sulaimani Journal for Engineering Science, vol. 1, no. 1, pp. 7-15, 2014.

[94] M. T. Chaichan, N. M. Ali, "Experimental investigation of the effect of exhausts gas recirculation (EGR) on NOx-Smoke trade-off for SIE fueled with blends of gasoline/bioethanol," Al-Rafidain Collage Journal, Issue 39, pp. 388-404, 2016.

[95] M. T. Chaichan, "EGR effects on hydrogen engines performance and emissions," International Journal of Scientific \& Engineering Research, vol. 7, No. 3, pp. 80-90, 2016.

[96] S. H. Khudhur, A. M. Saleh, M. T. Chaichan, "The effect of variable valve timing on SIE performance and emissions," International Journal of Scientific \& Engineering Research, vol. 6, no. 8, pp. 173 $179,2015$. 